\title{
Um novo olhar sobre a capacitação de professores a distância para inclusão Digital
}

\author{
Pricila Kohls dos Santos \\ pricilas@terra.com.br \\ Lucia Maria Martins Giraffa \\ giraffa@pucrs.br \\ Programa de Pós-Graduação em Educação \\ ARGOS - Grupo de Pesquisa Interdisciplinar em Educação a Distância \\ Pontifícia Universidade Católica do Rio Grande do Sul (PUCRS) \\ Porto Alegre - RS - Brasil
}

Resumo: Este artigo apresenta algumas reflexões acerca da questão envolvendo a Inclusão Digital relacionada à formação dos professores e a necessidade de ser utilizar os recursos da modalidade EAD para facilitar o acesso dos docentes à informação/formação e superar as distâncias num país continental como o Brasil. Apesar dos esforços governamentais e de instituições privadas existe uma parte significativa dos docentes que atuam nas escolas ainda não possuem a familiaridade e conhecimentos envolvendo o uso de recursos computacionais, Internet e suas ferramentas. Muitos professores não conseguem interromper suas atividades para adquirir tais conhecimentos e, mesmo que o façam, a rotina do seu trabalho e a pressão dos alunos para uso das redes sociais como elemento de apoio aos seus trabalhos é cada vez maior. Considerando-se este contexto criou-se uma proposta de curso onde se busca incluir o docente no ciberespaço através da vivência de situações que o permitam adquirir conhecimentos relacionados a softwares que ele necessita para organizar suas atividades profissionais.

Palavras-chave: Inclusão Digital, Formação Docente, EAD.

\begin{abstract}
This article presents some reflections concerning the subject involving the Digital Inclusion related to the teachers' formation and necessity of using EAD resources to make the teachers access to the information / formation easier and to overcome the distances in a continental country like Brazil. In spite of the government and private institutions efforts, a significant part of the teachers who work in schools still don't have possess the familiarity and knowledge involving the use of computer resources, Internet and their tools. Many teachers don't get to interrupt their activities to acquire such knowledge and, even if they do it, the routine of their work and the students' pressure for the use of the social nets as supporting element to there are assignments is constantly improving. Considering this context, a course proposal was created to try to include the teacher in the cyberspace through the existence of situations that allow them to acquire knowledge related to necessary important softwares they need to organize their professional activities.
\end{abstract}

Keywords: Digital Inclusion, Teacher Training, EAD.

\section{Introdução}


Segundo (Aretio, 2007), a sociedade da aprendizagem, que sucedeu a sociedade da informação, necessita cada vez mais desenvolver novas alternativas educacionais que incluam o usos de Tecnologias Digitais (TDs) tanto na formação docente, bem como na organização dos processos relacionados a aprendizagem dos alunos. Os avanços tecnológicos provocaram transformações nos meios de se transmitir informação e novas formas de trabalhar, de tomada de decisão, de aprendizagem, de organização do pensamento, de lazer e de entretenimento foram ofertadas à sociedade através das alternativas proporcionadas pela integração das várias tecnologias digitais, especialmente aquelas integradas e associadas a Web 2.0.

Com a constante evolução tecnológica, o conjunto de habilidades exigidas para se atuar nesta sociedade da aprendizagem é cada vez mais complexas, sendo cada vez mais necessária qualificação docente e o entendimento de que precisamos estar em constante processo de aquisição de novos conhecimentos e, por conseqüência, estarmos em constante estado de aprendizagem. Atualmente não é suficiente ter conhecimentos básicos acerca do uso do computador, faz-se necessário potencializar este conhecimento na forma de qualificação das relações sociais, da aquisição de conhecimento e das atividades relacionadas ao trabalho. Considerando este contexto, endereça-se o questionamento acerca da qualidade do uso das TDS e, para isto, abordar-se-á a Inclusão Digital como elemento articulador e propulsor desta reflexão. O tema Inclusão Digital é hoje um tema muito difundido, mas ainda pouco debatido no âmbito da formação docente. Parte-se do pressuposto que o público docente está incluído digitalmente ou tem mais facilidade para esta inclusão. Acredita-se que esta não é a realidade no contexto das escolas brasileiras.

Este artigo está dividido em 4 seções.

A seção 1 apresenta os conceitos relacionados a inclusão digital, letramento digital, alfabetização tecnológica e exclusão digital, tomando como base a formação docente para atuação na Educação Online, a qual se baseia no uso de computadores ligados à rede mundial Internet, considerando o ciberespaço criado pela Web 2.0 e suas ferramentas.

A seção 2 apresenta a descrição de um curso piloto de capacitação de professores para inclusão digital em que o principal objetivo será o de favorecer a apropriação das TDS de forma consciente, em que o indivíduo seja capaz de decidir quando, como e para que utilizá-la. Possibilitando assim uma atitude pró-ativa em relação a sua própria aprendizagem. A proposta considera que o curso será ministrado na modalidade EAD no formato de oficina virtual, cujo principal objetivo é aprender a trabalhar com aplicativos relacionados as TDs. Neste sentido o curso propõe-se trabalhar com a metodologia do "Aprender Fazendo", em que a cada atividade os estudantes poderão praticar os ensinamentos no momento em que são apresentados.

Na seção 3 discutem-se alguns aspectos importantes relacionados à formação de professores para inclusão digital considerando o uso da modalidade EAD.

Na seção 4 apresentam-se algumas considerações finais. As referências utilizadas para escrita deste artigo são colocadas ao final do texto.

\section{Exclusão Digital, Analfabetismo Digital e letramento Digital}

Quando se menciona a Exclusão Digital estamos falando da parcela da população que ficou á margem da sociedade tecnológica e da participação ações e interações que ocorrem na Internet. Atualmente a exclusão digital está na pauta de discussões do governo, entidades sociais e organizações do terceiro setor. Segundo 
censo do IBGE de 2003, que originou o mapa de exclusão digital no Brasil (vide Figura 1), os cinco estados mais incluídos são Distrito Federal, São Paulo, Rio de Janeiro, Santa Catarina e Paraná, e os cinco mais excluídos são o Maranhão, Piaú, Tocantins, Acre e Alagoas retratando de maneira clara que a exclusão é maior nos estados mais pobres do país.

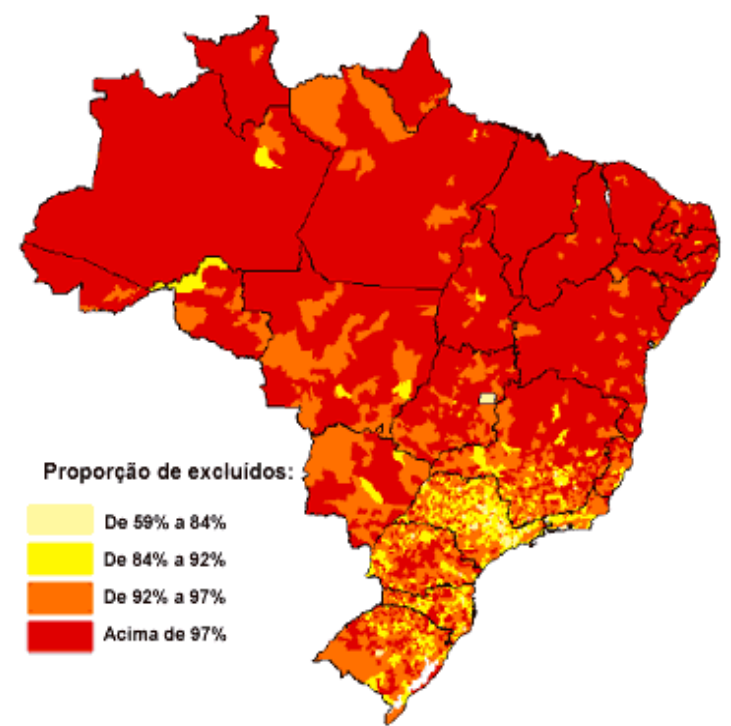

Figura 1: Mapa da exclusão digital no Brasil (Fonte: Mapa da exclusão digital/FGV)

Este mapa reforça o quanto estamos longe de um ser um país tecnologicamente evoluído, uma vez que mesmo tendo acesso a tecnologias de ponta ainda não se consegue disponibilizá-la para a maior parte da população.

Além da exclusão digital, outro tema requer atenção da sociedade: o analfabetismo digital, que está muito próximo do chamado analfabetismo funcional ${ }^{1} \cdot$., quando se considera o processo de aquisição das competências de leitura e escrita da língua materna. Considera-se um analfabeto digital todo usuário que entende o computador como um equipamento, mas não consegue entender seus mecanismos, potencialidades e funcionamento e, por conseqüência, não conseguem interpretar seus símbolos, códigos e potencialidades, interferindo na sua comunicação e produção mediada por este recurso tão necessário para sua ambientação na sociedade contemporânea.

O letramento digital, fazendo uma analogia ao termo letramento ${ }^{2}$ utilizado ao se falar sobre alfabetização, consiste em conhecer a tecnologia e fazer uso de seus meios e ferramentas de modo significativo no cotidiano em que está inserido. Ou seja, fazer uso das TDS para facilitar as atividades do dia-a-dia e, além disso, aprimorar o conhecimento sobre e "para que” a tecnologia disponível pode ser utilizada.

O conceito de inclusão digital tem haver com o acesso a computadores e a Internet por parte da população, sendo inevitável vincular este acesso às políticas públicas que buscam a diminuição das desigualdades sociais e materiais.

Medidas de inclusão digital são necessárias para possibilitarem a esses cidadãos agregarem cada vez mais conhecimento e desenvolverem o capital intelectual, colaborando para a evolução social, cultural e econômica de nosso país e caminhando para extinguir a divisão entre ricos e pobres de informação. (ALMEIDA; de PAULA, 2005, p.61).

Fazem-se necessária uma ação efetiva por parte de governo, entidades públicas e privadas para que a inclusão digital no Brasil deixe de ser uma utopia e venha a ser uma 
realidade presente nos diferentes estados brasileiros. Porém, além disso, a inclusão digital deve ser uma iniciativa de acesso às TDS, com o intuito de dominá-las partindo de uma compreensão crítica das mesmas, para assim auxiliar a diminuir as diferenças sociais, existentes em nosso país.

Após a breve discussão acerca dos conceitos apresentados, enfatiza-se a inclusão e o letramento digital como alternativa e/ou objetivo para a formação de professores, levando em consideração que o computador como ferramenta auxiliar do processo de ensino e de aprendizagem, deve ser considerado como um meio e não um fim em si mesmo. Ou seja, o usuário (docente ou discente) deve ter a oportunidade de utilizar o computador como suporte para suas descobertas e para isso quem trabalha com as TDS precisa estar preparado para agregar o recurso do computador, como elemento de apoio adicional, à sua prática pedagógica. Sendo que esta utilização do computador como ferramenta pedagógica, deve ocorrer tanto no ensino fundamental, médio, superior e na pós-graduação.

\section{A Formação de professores para inclusão digital considerando o uso da modalidade EAD}

A formação de professores para atuação no ciberespaço requer constante atualização e olhar crítico sobre as inovações que surgem. Destaca-se que hoje existe uma crença de senso comum que todo professor precisa ser um pesquisador e que o docente se coloque sistematicamente em condição de aprendiz, uma vez que deve estar em constante atualização.

A Educação a Distância é uma modalidade de ensino consolidada que visa levar a educação aos mais variados públicos e locais, democratizando o acesso à informação de forma a possibilitar a formação continuada, primando pela interação e a colaboração entre os sujeitos durante o processo de ensino e aprendizagem. A educação a distância viabilizada pelos Ambientes Virtuais de Aprendizagem (AVA) deve ser um espaço para se viver no fazer e de reflexão sobre o fazer, de modo que, professores e estudantes se tornem diferentes, resignificando, a cada ação, sua presença na comunidade. Por este motivo optamos por este espaço para desenvolver o projeto para Formação de Professores para Inclusão Digital, por entender a potencialidade gerada a partir das relações que podem emergir das comunidades constituídas pelos AVA. Formando elos entre diferentes autores/atores formamos e constituímos redes que se materializam na apropriação tecnológica, flexibilização, reflexibilidade, interatividade e sentimento de pertença.

Tal proposta se consolida pela necessidade de formação de professores para o uso consciente das TDS, no tocando ao conhecimento das ferramentas e recursos disponíveis e análise das mesmas com um olhar investigativo e inovador, procurando assim identificar possibilidades de uso em sua prática docente, visando a sua qualificação e do processo de ensino e aprendizagem. Para que isto aconteça faz-se necessário o desenvolvimento de competências que ressaltem a criatividade, a motivação, a pró-atividade, a investigação, capacidade de inovar, a articulação teoriaprática. Cada vez mais é necessário que o docente seja capaz de aliar o conteúdo trabalhado com seus alunos ao cotidiano destes discentes, criando e recriando um ambiente rico de produção do conhecimento em que todos são ao mesmo tempo autores e aprendizes, tendo como base a troca de experiências resultantes desta interação.

O curso hora proposto está baseado numa metodologia que se divide em três momentos: apropriação e reflexão sobre os pressupostos teóricos e conhecimento e/ou reconhecimento dos recursos da web 2.0 e serviços online disponíveis e por fim a 
Internet como espaço para educação continuada. Em cada um destes momentos são propostas atividades práticas, tanto para apropriação de habilidades tecnológicas (por meio a atividades individuais e em grupo) como para propor uma reflexão acerca do que está sendo trabalhado e suas implicações na prática docente, buscando-se desta forma um caminho para a motivação necessária à inovação da prática docente. Em que a diversidade de interesses seja atendida através de caminhos personalizados viabilizados por uma arquitetura pedagógica que prime pelas inquietações individuais como mola propulsora para o saber coletivo. Utilizando-se para isto a lógica de abstrair, na perspectiva de extrair tudo o que não pertence ao problema para conectar, ou seja, identificar conexões existentes entre as individualidades de cada um dentro do ambiente.

\section{A estrutura do curso para capacitação dos professores}

Este curso é desenvolvido na modalidade a distância, utilizando para isto a plataforma Moodle (www.moodle.org). O curso tem duração de 60h, e desenvolvido no período dois meses. Neste período são realizadas atividades de cunho teórico-práticas, utilizando os diferentes recursos e ferramentas disponíveis no Moodle, tais como, fórum de discussão, bate-papo, glossário, arquivos com leituras de apoio, lição online, livro, e recursos de multimídia integrados no ambiente, através das suas salas de aula virtuais, utilização de recursos de áudio, vídeo e animações disponíveis na Internet, entre outros.

Dentre os temas abordados no curso estão: inserção tecnológica, inclusão digital, TDs na educação, conceitos básicos de Informática, software livre, recursos da web (2.0 e 3.0), serviços online, educação continuada através da Internet. Todos os temas, utilizados como base para aquisição das competências relacionadas às tecnologias, estão relacionados à atividades práticas vislumbrando possibilidades de uso em sala de aula.

Assim o curso tem a seguinte estrutura, organizada nos seguintes espaços:

- Carta de Navegação: caminhos possíveis de serem trilhados durante a realização do curso, panorama geral do ambiente do curso;

- Conceitos Iniciais: local em que estão disponibilizados conceitos e atividades introdutórias envolvendo, conceitos básicos de informática, software livre.

- Biblioteca Virtual: local onde estão disponibilizados os textos, links, arquivos diversos (formatos variados de mídia) com os materiais relacionados aos aportes teóricos;

- Atividades do Curso: cronograma com o conjunto de atividades que os alunos devem desenvolver ao longo do curso;

- Descobertas: local para compartilhar saberes adquiridos, aprendizagens, resultado de buscas na Internet, convivência e troca de idéias viabilizada através dos fóruns de discussão e salas de bate-papo do ambiente e apresentadas com o uso de glossários e wikis. Os alunos colocam as novas palavras e conceitos na Wiki e discutem qual o melhor significado para eles. Depois de chegarem a um consenso estes novos itens são colocados no glossário.

As figuras 2 e 3 apresentam a interface do ambiente do curso. 


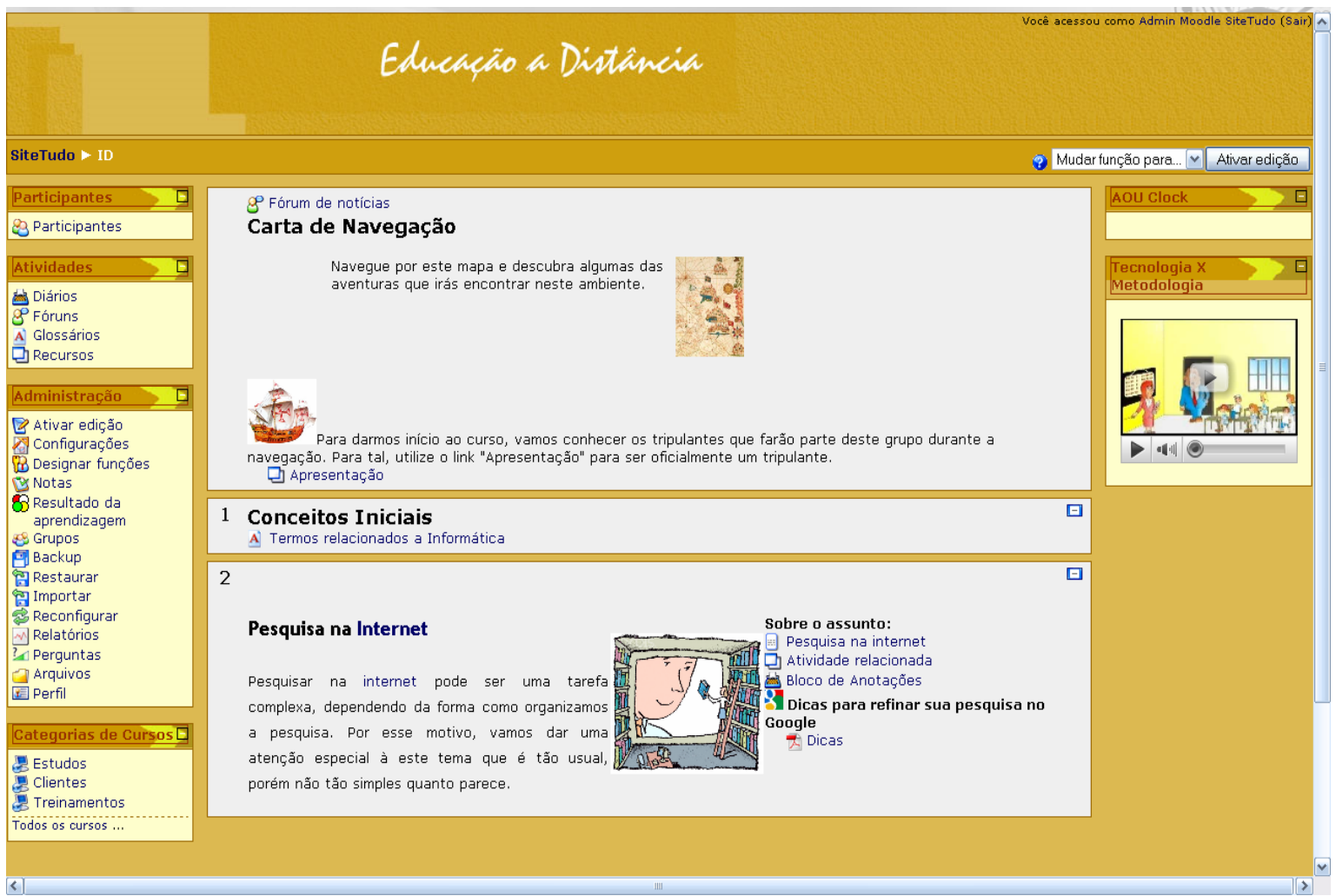

Figura 2: Interface do Ambiente - Página inicial

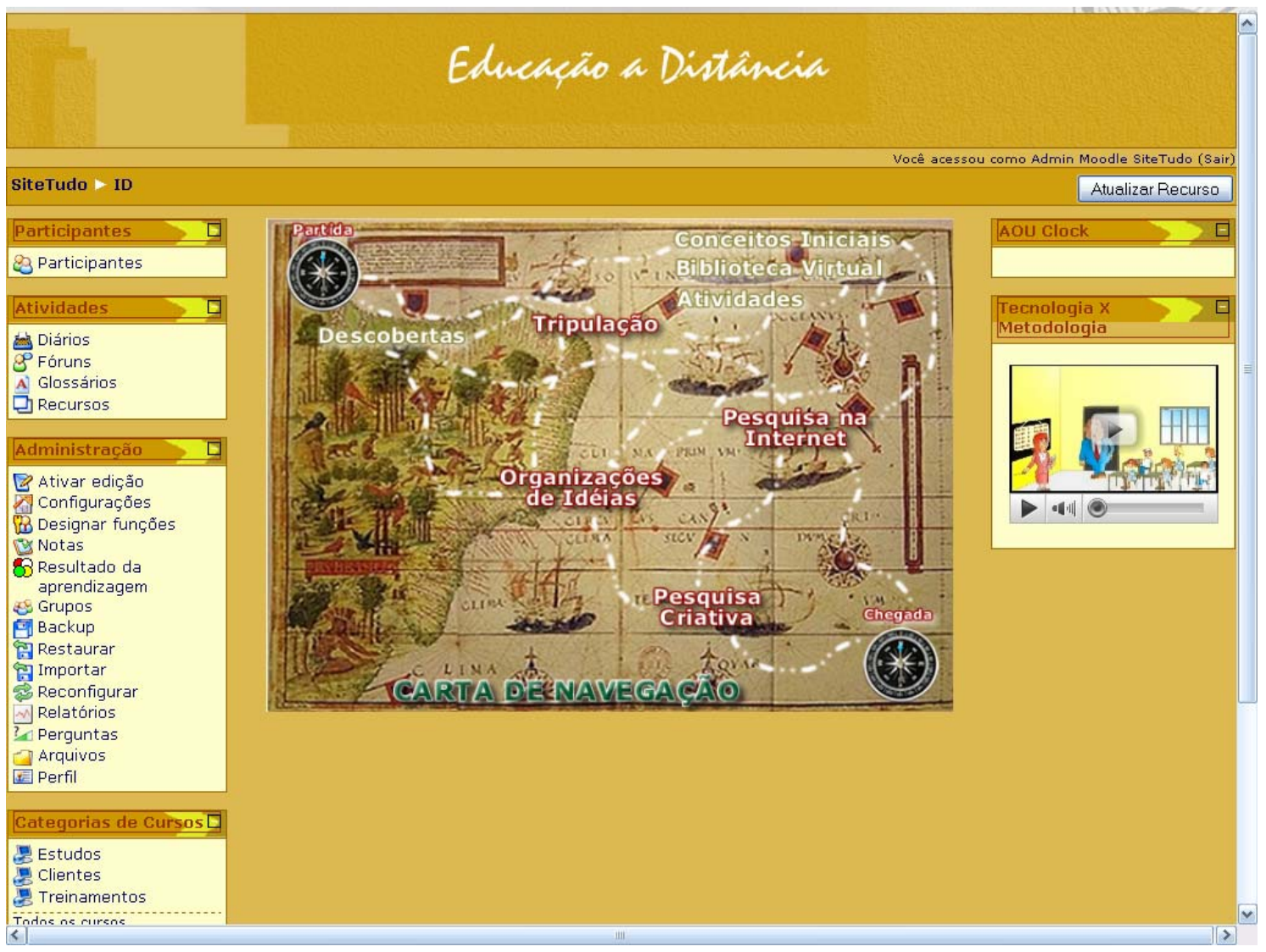

Figura 3: Interface do Ambiente - Carta de Navegação

As atividades propostas envolvem a utilização de aplicativos mais comuns, tais como editores de texto, editor de apresentação, editor de imagens do Picasa (o qual 
permite a editoração de imagens, fotos, figuras e o uso do Movie Maker para criação de animações e sua posterior publicação no YouTube, sem necessidade de formação complexa ou conhecimento profundo destas ferramentas). A concepção do curso busca auxiliar o professor, a utilizar os mecanismos e recursos disponíveis no próprio aplicativo para facilitar o seu dia-a-dia e simplificar suas atividades rotineiras. Para tanto, ao longo do curso, antes de se introduzir uma nova atividade relacionada a um determinado software é realizado um levantamento de expectativas do professor e a partir de um banco de atividades pré-organizadas seleciona-se quais as mais adequadas àquele grupo de professores. Desta forma, pode-se adaptar o curso as necessidades de cada grupo de professores, respeitando-se sua realidade escolar e aspirações pessoais.

Um exemplo de tal atividade relacionado ao editor de textos é gerar referências bibliográficas automaticamente a partir de comandos simples. Assim sendo, são desenvolvidas atividades síncronas e assíncronas buscando a participação efetiva dos participantes na construção coletiva do conhecimento. A seguir serão apresentadas algumas atividades e seus pré-requisitos, sendo divididos entre requisitos funcionais (técnicos) e não-funcionais (de qualidade).

\section{Atividades:}

\section{Conhecendo a tripulação}

Escolha uma imagem que o identifique, em seguida utilize a ferramenta FotoFlexer [http://fotoflexer.com/] para editar esta imagem e inserir uma foto sua na mesma. O arquivo final dará origem a sua apresentação inicial ao grupo. A sua criatividade é o limite.

\section{Requisitos funcionais:}

- Identificar arquivo de foto no computador;

- Conhecer as diferentes extensões de arquivos de imagem;

- Identificar o tamanho de arquivo;

- Acesso a internet;

\section{Requisitos não-funcionais}

- Recriar uma imagem a partir de outras;

- Utilizar efeitos e ferramentas com criatividade.

\section{Pesquisa na internet}

Tomando como referência o material disponível no ambiente, faça uma pesquisa na Internet sobre o termo "Inclusão Digital" utilizando o mecanismo de busca da Google. Observe os resultados apresentados e anote em seu "Bloco de anotações virtual”. Em seguida faça a mesma pesquisa utilizando o metabuscador MetaCrawer, ou escolha outra de sua preferência, faça o mesmo exercício de observação e anotação dos resultados. Posteriormente compare os resultados descrevendo as principais diferenças percebidas entre as duas em seu bloco de anotações.

\section{Requisitos funcionais:}

- Acessar a internet e site de busca e metabusca;

- Utilizar ferramenta (diário) para anotações;

\section{Requisitos não-funcionais}

- Observar e interpretar os diferentes resultados obtidos com a pesquisa.

\section{Pesquisa criativa}

Acesse 0 Portal do Professor [http://portaldoprofessor.mec.gov.br/] Recursos educacionais e Cursos e materiais e selecione um item para ser utilizado pelo grupo para elaboração de uma atividade que será realizada pela grupo.

\section{Requisitos funcionais:}


- Acessar a internet;

- Identificar recursos disponíveis no Portal do Professor;

- Copiar endereço da internet;

- Fazer download de recurso;

\section{Requisitos não-funcionais}

- Selecionar recursos disponíveis no Portal do Professor;

- Propor utilização do recurso selecionado.

\section{Organização de idéias}

A partir da leitura do texto "Exclusão digital: problemas conceituais evidencias empíricas e políticas publicas” faça uma síntese das principais idéias contidas no texto. Para isto utilizaremos a ferramenta Explora Tree [http://www.exploratree.org.uk/], que é um organizador online de mapas mentais e/ou conceituais.

\section{Requisitos funcionais:}

- Acessar a internet;

- Fazer registro de usuário;

- Escolher modelo;

- Salvar arquivo;

- Enviar arquivo salvo;

- Identificar extensão do arquivo;

- Identificar o tamanho de arquivo;

\section{Requisitos não-funcionais}

- Sintetizar idéias;

- Organizar pensamento e reflexões.

A partir dos pré-requisitos de cada atividade e de acordo com as expectativas levantadas com o grupo pretendes-se, através da analise dos dados, preencher lacunas técnicas através de atividades paralelas e com a elaboração de um metacurso que possa suprir essas necessidades, ficando visível este caminho apenas para quem necessite trilhá-lo. Tal abordagem se justifica pela intenção de realizar um trabalho comparativo entre um curso formal, em que todos os participantes são colocados em mesmos níveis e trechos de caminhada, e um curso organizado por grupos separados de acordo com os perfis.

Assim a metodologia de trabalho que serve de base para criação deste curso busca oportunizar aos participantes situações de aprendizagem compatíveis com suas necessidades habituais (relacionadas aos afazeres docentes) e demonstrar que isto é possível mesmo na modalidade a distância. Entende-se que as redes de aprendizagem, que se constituem a partir das interações através das Tecnologias Digitais, possibilitam que grupos de pessoas unidas por objetivos comuns, aprendam juntas no horário-localritmo mais adequado para elas. Transformando assim, os cursos a distância em janelas para o mundo do conhecimento através de espaços compartilhados, oferecendo acesso a idéias, perspectivas, culturas, novas informações e múltiplos olhares sobre um mesmo tema, facilitando e enriquecendo a compreensão da diversidade cultural.

Para o alcance dos objetivos do curso é necessário a elaboração conjunta de conceitos e significados a cerca das temáticas apresentadas, levando em consideração as vivências, histórias e anseios de cada um dos participantes. Isto é necessário para que estas ações possam ser contextualizadas na virtualidade como forma de apropriação da tecnologia, visando o exercício da cidadania e o empreendedorismo ao utilizar e/ou refletir sobre o uso das TDS. Ou seja, 


\begin{abstract}
"Apropriar-se das tecnologias significa desenvolver e aperfeiçoar habilidades que vão de tarefas básicas, como escrever um e-mail ou reconhecer um spam, a atividades complexas, como pesquisar de maneira eficaz, acessar serviços ou produzir um vídeo digital e transmiti-lo via web. Isso quer dizer que muitos aspectos inclusão digital não estão nas máquinas nem na relação com as máquinas, e sim no processo global de inclusão social." (ASSUMPÇÃO; MORIS, 2006)
\end{abstract}

Neste sentido foi necessário elaborar este curso piloto no formato de Oficina Virtual, com o intuito de seus participantes poderem ser multiplicadores desta prática para alunos ingressantes das Universidades, tendo em vista que este olhar/prática pode transformar e/ou ressignificar a ação destes alunos enquanto cidadãos conscientes e sabedores de seu potencial, bem como de seus direitos. Qualificando assim o produto, processo e seu agente.

"Ser moderno é encontrar-se num ambiente que promete aventura, poder, alegria, crescimento, autotransformação e transformação das coisas em redor - mas ao mesmo tempo, ameaça destruir tudo o que temos tudo o que sabemos tudo o que somos." (BERMAN, 1989)

\title{
5. Considerações finais
}

O terreno da Inclusão Digital ainda é pouco investigado no tocante ao uso tecnologia considerando as relações sociais oriundas das atividades no ciberespaço, definido por (Levy, 2005) como o espaço de comunicação aberto pela interconexão mundial dos computadores e das memórias dos computadores. Onde ele enfatiza a codificação digital, a qual condiciona o caráter plástico, fluido, calculável e tratável em tempo real, hipertextual, interativo e virtual, marcas distintivas deste espaço.

Transformar este terreno virtual em algo que se possa utilizar na escola não é somente algo possível, como deve ser buscado de forma efetiva na formação do docente.

“As tecnologias evoluem em quatro direções fundamentais: Do analógico para o digital (digitalização)

Do físico para o virtual (virtualização) Do fixo para o móvel (mobilidade) Do massivo para o individual (personalização) Carly Fiorina, ex-presidente Hewllet-Packard-HP"

Partindo desta reflexão acrescentamos uma $5^{\text {a }}$ direção que se faz necessária em tempos de cibercultura e comunidades virtuais de aprendizagem: do individual para o coletivo (comunitário-solidário). A aprendizagem ocorre em redes de cooperação mediadas pelas modernas Tecnologias Digitais (TDs) com autoria compartilhada o que muda a tradicional relação de propriedade da informação e por conseqüência do conhecimento A educação passa a ser um processo da sociedade e não mais apenas responsabilidade da escola. Aprende-se na sala de aula, na LanHouse, no Orkut, no Facebook, no Twitter, no MSN, no Second Life, em livros impressos e/ou digitais, na televisão, no cinema, teatro,... aprende-se em qualquer lugar e de diversas formas.Uma vez que amplia-se o espaço pedagógico deve-se ampliar as maneira de se fazer a formação docente. 


\section{Referências}

ALMEIDA, Lília Bilati, de PAULA, Luiza Gonçalves. O Retrato da Exclusão Digital na Sociedade Brasileira. Revista de Gestão da Tecnologia e Sistemas de Informação. Journal of Information Systems and Technology Management. Vol. 2, No. 1, 2005, pp. 55-67. Texto disponível em:

$<$ http://www.buscalegis.ufsc.br/revistas/files/journals/2/articles/30689/public/3068932934-1-PB.pdf>. Acesso em: 18/04/2010.

ARETIO, Lorenzo Garcia; CORBELLA. Marta Ruiz; FIGAREDO, Daniel Dominguez. De la Educación a Distancia a La Educación Virtual. Barcelona: Ariel, 2007.

ASSUMPÇÃO, Rodrigo, MORI, Cristina. Inclusão Digital: Discursos, práticas e um longo caminho a percorrer. Disponível em:

$<\underline{\text { http://www.inclusaodigital.gov.br/noticia/inclusao-digital-discursos-praticas-e-um- }}$ longo-caminho-a-percorrer/>. Acesso em: 10/04/2010

BERMAN, Marshall. Tudo o que é sólido se dissolve no ar. Edições 70, Lisboa, 1989.

LEVY, Pierre. Cibercultura. São Paulo: Ed. 34, 2005 (5 $5^{\mathrm{a}}$ reimpressão).

Mapa exclusão digital Abril de 2003. Disponível em:

<http://integracao.fgvsp.br/ano6/06/pesquisas.htm>. Acesso em: 18/04/2010

\footnotetext{
${ }^{1}$ Denominação dada à pessoas que conhecem as letras e decodificam seus símbolos, porém não possuem a habilidade de interpretação de textos, ou seja, a capacidade de interpretar, compreender, criticar, ressignificar e produzir conhecimento.

${ }^{2}$ Denominação dada ao processo que vai além da decodificação do sistema alfabético da escrita e incorpora a compreensão dos usos sociais da escrita.
} 